\title{
Antibacterial antibiotic-induced drug reaction with eosinophilia and systemic symptoms (DRESS) syndrome: a literature review
}

\author{
Shiva Sharifzadeh ${ }^{1} \cdot$ Amir Hooshang Mohammadpour $^{1,2} \cdot$ Ashraf Tavanaee $^{3} \cdot$ Sepideh Elyasi $^{1}$ (E)
}

Received: 10 December 2019 / Accepted: 18 September 2020 / Published online: 6 October 2020

(C) Springer-Verlag GmbH Germany, part of Springer Nature 2020

\begin{abstract}
Background Drug reaction with eosinophilia and systemic symptoms syndrome (DRESS) is a delayed infrequent potentially lifethreatening idiosyncratic drug reaction. Aromatic anticonvulsants and allopurinol are the most frequent causative agents. However, various reports of antibiotic-induced DRESS are available. In this review, we try to summarize reports of antibacterial antibiotic-induced DRESS focusing on characteristics of DRESS induced by each antibiotic group.

Methods The data were collected by searching PubMed/MEDLINE and ScienceDirect. The keywords used as search terms were "DRESS syndrome," "drug-induced hypersensitivity syndrome (DIHS)," "antibiotics," "antimicrobial," and names of various antimicrobial groups. Finally, 254 relevant cases with a definite or probable diagnosis of DRESS based on RegiSCAR criteria were found until 30 May 2020 and reviewed.

Results and conclusion Totally, 254 cases of antibacterial antibiotic-induced DRESS are reported. Most of them are related to antituberculosis drugs, vancomycin, and sulfonamides, respectively. Rash and fever were most frequent clinical findings. Eosinophilia and liver injury were the most reported hematologic and visceral organ involvement, respectively. Most of the patients are managed with systemic corticosteroids. The death occurred in 16 patients which most of them experienced liver or lung involvement. The reactivation of various viruses especially HHV-6 is reported in 33 cases. The mean latency period was 29 days. It is necessary to perform thorough epidemiological, genetic, and immunological studies, also systematic case review and causality assessment, as well as well-designed clinical trials for better management of antibiotic-induced DRESS.
\end{abstract}

Keywords DRESS syndrome · Drug-induced hypersensitivity syndrome (DIHS) · Antibiotics · Antimicrobial agents

\section{Introduction}

Drug reaction with eosinophilia and systemic symptoms (DRESS), also known as drug-induced hypersensitivity syndrome (DIHS), and DIDMOHS (drug-induced delayed multi-

Electronic supplementary material The online version of this article (https://doi.org/10.1007/s00228-020-03005-9) contains supplementary material, which is available to authorized users.

Sepideh Elyasi

elyasis@mums.ac.ir

1 Department of Clinical Pharmacy, School of Pharmacy, Mashhad University of Medical Sciences, P.O. Box 91775-1365,

Mashhad, Iran

2 Pharmaceutical Research Center, Mashhad University of Medical Sciences, Mashhad, Iran

3 Department of Infectious Disease, School of Medicine, Mashhad University of Medical Sciences, Mashhad, Iran organ hypersensitivity syndrome) [1], is a delayed potentially fatal multi-organ systemic idiosyncratic drug reaction $[2,3]$. The prevalence of DHS ranges between 1 in 1000 and 1 in 10,000 exposures. It occurs more frequently in females [2-4]. Symptoms typically develop after 2 to 6 weeks of medication use. Re-exposure to the same drug may cause symptoms even within $24 \mathrm{~h}$. The symptoms may last for weeks or even months after the medication discontinuation [5]. DRESS induces by Th2-lymphocytes and $\mathrm{CD} 8^{+}$cells. Th2 cells probably induce type IVb hypersensitivity response affecting the skin, while $\mathrm{CD} 8^{+} \mathrm{T}$ cells cause damage to internal organs [6]. Furthermore, a specific defect in the metabolism and detoxification of a drug can happen in phenotypic susceptible patients. Then the toxic metabolite acts as a hapten, initiating an immune response. In other words, genetic polymorphisms of these elimination mechanisms have been implicated in several skin drug reactions, like DRESS [2, 7]. In lots of previous reports, DRESS occurrence might be associated with the human herpesvirus (HHV)-6 and 7, Epstein-Barr virus (EBV), 
and cytomegalovirus (CMV) reactivation $[2,8]$. HHV-6 is the most reported one [9].

DRESS reaction characterized by a generalized exanthematous morbilliform rash, fever, enlarged lymph nodes, internal organ involvement (usually the liver and kidneys), and hematologic findings including leukocytosis with hypereosinophilia $[2,3]$. Skin presentations can be as exfoliative erythroderma, follicular, or nonfollicular pustules, purpuric lesions or blisters, and tense bullae induced by dermal edema. Typically involved sites are the face, upper trunk, and extremities [5]. Additionally, encephalitis, aseptic meningitis, myositis, bleeding, thyroiditis, respiratory distress syndrome, pericarditis, myocarditis, pneumonitis, colitis, pancreatitis, hypotension, interstitial nephritis, arthritis, arthralgia, and orchitis have been reported as organ involvements which typically occurs 1-2 weeks after skin eruption [5]. The pulmonary manifestation of DRESS presents in a wide spectrum from mild cough or dyspnea with nonspecific interstitial changes on chest imaging to acute respiratory distress syndrome (ARDS) with lifethreatening hypoxic respiratory failure [10]. The mortality rate due to DRESS is reported between 10 and 30\% [11]. However, Kardaun et al. reported a considerably lower rate in the acute phase, probably reflecting bias in published retrospective studies [12]. Fulminant hepatitis is the main cause of death associated with this syndrome, occurring in 5 to $10 \%$ of cases [13]. Myocarditis and respiratory failure are other main causes of death [10].

Various criteria have been established for the identification of DRESS syndrome. The Japanese Research Committee on Severe Cutaneous Adverse Reaction (J-SCAR) and the European registry on severe cutaneous adverse drug reactions (RegiSCAR) are the most commonly used clinical diagnostic criteria [14]. RegiSCAR seems to be more accurate and comprehensive but the J-SCAR considered viral reactivation as a diagnostic criterion in contrast to RegiSCAR. Besides, there are some other accessory tools for its confirmation like the lymphocyte transformation test (LTT), the intradermal test (IDT), and skin biopsy [15]. LTT could not be used for diagnosis but skin biopsy besides using diagnostic criteria like RegiSCAR could be helpful.

Fortunately, this reaction is usually reversible, with a low incidence of residual damage or mortality, in the case of timely discontinuation of antibiotics and the use of topical or systemic corticosteroids $[16,17]$. But the efficacy of systemic corticosteroids is unclear and randomized clinical trials are lacking [18]. Experts recommend this measure for patients with life-threatening hepatitis, pneumonia, or nephritis [16]. Immunosuppressive therapy with agents such as cyclophosphamide or cyclosporine may be even essential in steroidresistant cases [19]. In severe DRESS, plasma exchange or intravenous immunoglobulin (IVIG) has also been used, although data on this is limited [16]. Supportive procedures are also helpful, including fluid and electrolyte management and antihistamines for cutaneous symptoms relief [16].

Aromatic anticonvulsant drugs (e.g., carbamazepine, phenytoin, and phenobarbital) and allopurinol are the most common offending medications. However, various reports of DRESS induced by antimicrobial agents including vancomycin, sulfonamides, beta-lactams, minocycline, and anti-viral medications are available $[1,3,4,16]$. A recently published case series proposed that $15-37 \%$ of DRESS syndrome may be caused by antibiotics [16]. In an electronic health record review in the USA, from 1980 to 2016, antibiotics were attributed to DRESS syndrome in $74 \%$ of cases (vancomycin [39\%], $\beta$-lactams [23\%], fluoroquinolones [4\%], tetracyclines [4\%], and sulfonamides [3\%]) [20]. Overall, the severity of the antibiotic-induced DRESS in comparison with other culprits is controversial. Some studies reported that it was less severe than anticonvulsant or allopurinol-induced DRESS $[21,22]$. But Trubiano et al. proposed that it is associated with high hospital admission and longer length of stay and higher mortality rate [23]. Many questions remain to be answered about the DRESS syndrome induced by antibiotics. In this review, we have collected all available reports of DRESS syndrome with antibacterial antibiotics agents.

\section{Methods}

The data were collected by searching in PubMed/MEDLINE and Scopus. The keywords used as search terms were "DRESS syndrome," "drug-induced hypersensitivity reaction (DIHS)," "antibiotics," "antimicrobial," "beta-lactams," "penicillins," "cephalosporines," "aminoglycosides," "macrolides," "fluoroquinolones," "vancomycin \& teicoplanin," "glycopeptides," "tetracyclines," "clindamycin," "linezolid," "sulfonamides," and "antituberculosis." Criteria for inclusion were as follows: full-text case reports/series available online, without a limit of the publication date on patients with a definite or probable diagnosis of antibacterial antibiotic induced DRESS based on RegiSCAR criteria (when RegiSCAR score was unavailable it was calculated by the authors based on the information from the case report). Criteria for exclusion were as follows: duplicate publications, unavailability of full-text, language other than English, and review articles. Data collection was carried out between October 2019 and 30 May 2020. By searching these databases, 299 articles were found. Corresponding and first authors performed the search process and initial selection of eligible studies. The first author checked the eligibility of the studies based on RegiSCAR criteria. After excluding unrelated $(n=29)$ and duplicated $(n=38)$ articles and also the review or general articles $(n=30), 202$ eligible articles (case reports/ series) were review. Out of 202 articles, two articles were excluded for full-text unavailability, 13 for not being available 
in English, 31 articles as reported antiviral or antifungal induced DRESS, and 18 articles as the DRESS diagnosis was not definite or probable based on RegiSCAR criteria. Finally, a total of 138 relevant articles up to the date of preparation (May 30, 2020) were included for review that 254 cases were reported in these articles (Fig. 1). The related articles are summarized in Table 1 supplementary file.

\section{Discussion}

There are reports of DRESS with various antimicrobial categories that are reviewed below in a classified manner. For better understanding of the differences between various antibiotic groups, we summarized the important information in 4 tables. In Table 1, the prevalence of DRESS with various antibacterial antibiotic categories are reported. In Table 2, mean latency period and percentage of eosinophilia occurrence are presented for each antibiotic group. In Table 3, visceral organ involvement of different antibiotic groups is
Table 1 Comparison of DRESS prevalence between various antibiotic groups

\begin{tabular}{ll}
\hline Antibiotic category & Number of reported cases $(\%)$ \\
\hline Penicillin & $22(8.66)$ \\
Cephalosporin & $10(3.94)$ \\
Carbapenem & $3(1.18)$ \\
Aminoglycoside & $2(0.79)$ \\
Antituberculosis & $107(42.13)$ \\
Macrolide & $2(0.79)$ \\
Fluoroquinolone & $5(1.97)$ \\
Glycopeptides & $46(18.11)$ \\
Tetracycline & $21(8.27)$ \\
Lincosamide & $3(1.18)$ \\
Sulfonamide & $23(9.06)$ \\
Nitrofurantoin & $3(1.18)$ \\
Linezolid & $1(0.39)$ \\
Daptomycin & $1(0.39)$ \\
Others & $5(1.97)$ \\
Total & 254 \\
\hline
\end{tabular}

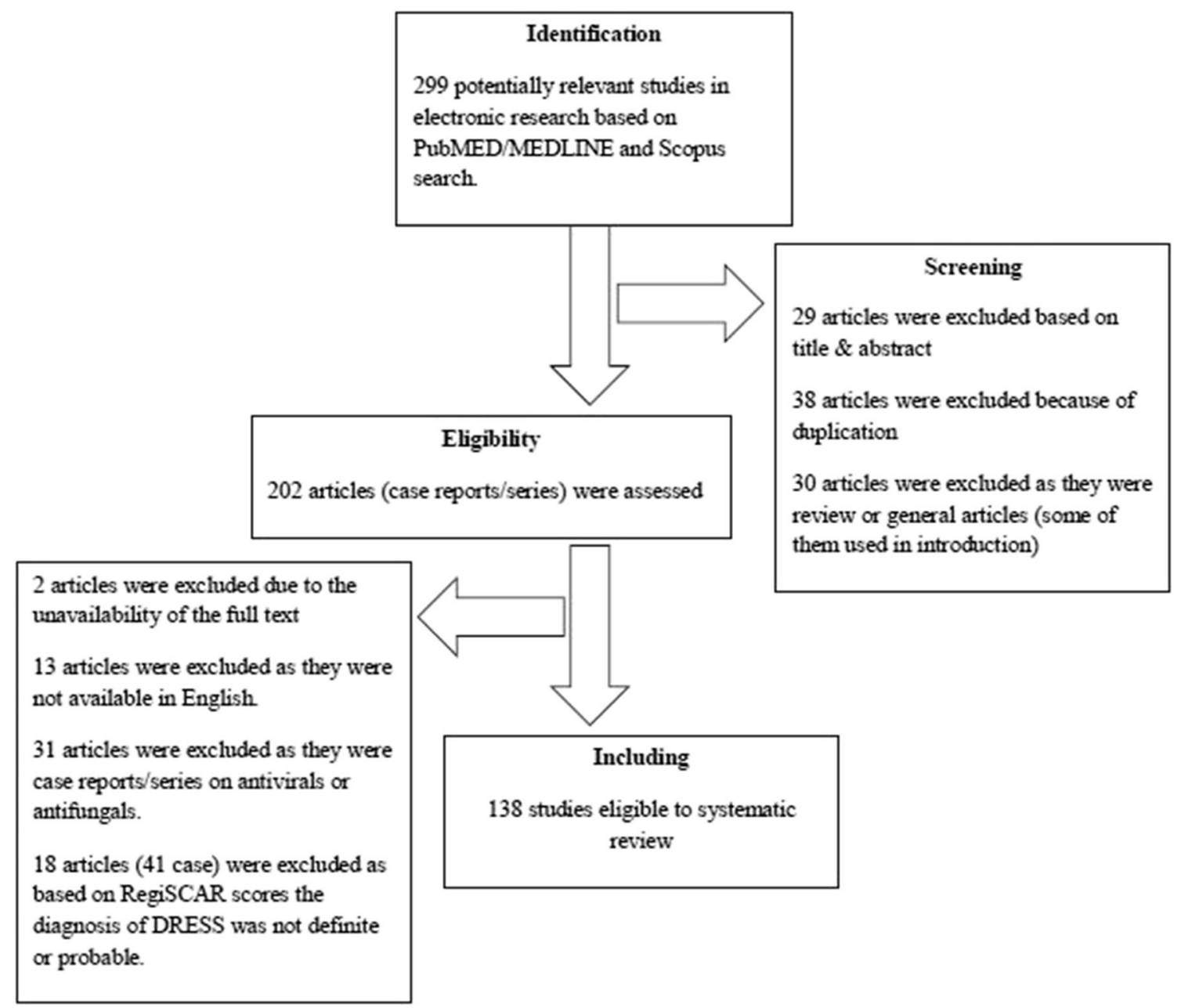

Fig. 1 Diagram of the study selection process 
Table 2 Comparison of mean latency period and eosinophilia between various antibiotic groups

\begin{tabular}{llll}
\hline Antibiotic category & Mean latency period (day) & Eosinophilia (\%) & Mean eosinophil count (\%) \\
\hline Penicillin & 16.53 & 81.8 & 32.94 \\
Cephalosporin & 19.4 & 100 & 29.63 \\
Carbapenem & 4 & 100 & 28.5 \\
Aminoglycoside & 31.5 & 100 & 40 \\
Antituberculosis & 34.56 & 95.33 & 32 \\
Macrolide & 5.5 & 100 & 47 \\
Fluoroquinolone & 7.4 & 100 & 49.75 \\
Glycopeptides & 21.23 & 100 & 20.08 \\
Tetracycline & 28.48 & 95.24 & 31.5 \\
Lincosamide & 12.33 & 66.67 & 19.5 \\
Sulfonamide & 55.22 & 91.3 & 16.5 \\
Nitrofurantoin & 5.33 & 66.67 & - \\
Linezolid & 7 & 100 & - \\
Daptomycin & 2 & 100 & - \\
\hline
\end{tabular}

defined. Finally, in Table 4, patients' outcome for various antibiotics induced DRESS is accessible.

\section{Penicillins}

Out of total 254 cases summarized in this review, 22 cases were related to penicillins which were corresponded to $8.6 \%$ of all cases. Limited numbers of penicillin-induced DRESS reaction are reported. Among these 22 cases, 17 cases are occurred by co-amoxiclav and piperacillin-tazobactam (Pip/ Taz), which are beta-lactam-beta-lactamase antibiotics. It could propose this hypothesis that combination of penicillins with beta-lactamase may be more prone for DRESS syndrome triggering.

The latency period differed between cases from days to more than 1 month for amoxicillin-clavulanic acid. Most of cases $(85.71 \%)$ experienced liver involvement but recovered completely. There is also a report of DRESS with amoxicillinClavulanic acid in a pregnant woman, who presenting with erythematous plaques on the abdomen, developing cardiac tamponade because of eosinophilic perimyocarditis and an interstitial pneumonitis 5 weeks after exposure. Her symptoms improved after oral corticosteroid therapy and she had an uncomplicated, on-time delivery [24].

For Pip/Taz, the latency period was more than 2 weeks in all reported cases. In Cabanas et al., case series is stated that Pip/Taz is the principal cause of DRESS in their hospital, accounting for $26 \%$ of studied cases at the allergy department between 2006 and 2010 [3]. However, we just found 11 cases of Pip/Taz-induced DRESS (account for $4.33 \%$ of all collected antibiotic-induced DRESS). Circulating antigens derived from piperacillin and the drug-derived epitopes on proteins have been identified and completely described by Whitaker et al. [25] and proved that long-term treatment with very high doses of this reactive drug could be a risk factor for developing a T cell--mediated drug reaction. Drug-peptide conjugates derived from modified albumin clearly represent functional Ags for T cells and may indeed function as immunogens. As the half-life of modified human serum albumin is 19 days, it may also clarify why the meantime of skin symptom resolution is about 18 days, which is slightly shorter than that usually reported for DRESS syndrome (3-6 weeks; mean \pm SD = $6.4 \pm 9.4$ weeks) [26].

The liver was the main involved internal organ in DRESS induced by Pip/Taz [35]. It seems that DRESS induced by piperacillin is milder, with a benign course and favorable prognosis [21, 22].

In a case of Pip/Taz-induced DRESS, which occurred with a 14-day latency period, patient reported numbness and paresthesia of the forearm during intravenous Pip/Taz infusion, 2 days before DRESS occurrence that may be the sign of upcoming DRESS [1].

Finally, a case could be mentioned that a patient experienced both acute generalized exanthematous pustulosis (AGEP) and DRESS with Pip/Taz, which is a rare finding [27].

Amoxicillin seems to have some role in triggering the DRESS in patients already showing signs of intolerance to sulfasalazine, but its role in the development of DRESS syndrome in people with no previous history remains unclear [4, 28-30]. Mardivirin et al. reported seven cases of DRESS flare with amoxicillin which was induced by other drugs. This reaction should be known because sometimes amoxicillin is considered as culprit drug, but the true offender drug had been taken for many weeks. It may cause a delay in the withdrawal of the true offending drug. It should be noted that complete manifestations of DRESS were too short after amoxicillin use to consider it as the culprit drug in these cases [31]. 
Table 3 Comparison of visceral organ involvement between different antibiotic groups

\begin{tabular}{|c|c|c|}
\hline Antibiotic category & Visceral organ involvement & Number (\%) \\
\hline \multirow[t]{4}{*}{ Penicillin } & Liver & $21(95.45)$ \\
\hline & Kidney & $7(31.82)$ \\
\hline & Lung & $1(4.5)$ \\
\hline & Myocardium & $2(9.09)$ \\
\hline \multirow[t]{3}{*}{ Cephalosporin } & Liver & $8(80)$ \\
\hline & Kidney & $3(30)$ \\
\hline & Lung & $1(10)$ \\
\hline Carbapenem & Liver & $3(100)$ \\
\hline Aminoglycoside & Liver & $2(100)$ \\
\hline \multirow[t]{6}{*}{ Antituberculosis } & Liver & 77 (71.96) \\
\hline & Kidney & $34(31.78)$ \\
\hline & Lung & $10(9.35)$ \\
\hline & Myocardium & $1(0.93)$ \\
\hline & CNS & $5(4.67)$ \\
\hline & GI & $1(0.93)$ \\
\hline \multirow[t]{2}{*}{ Macrolide } & Liver & $1(50)$ \\
\hline & Kidney & $2(100)$ \\
\hline \multirow[t]{3}{*}{ Fluoroquinolone } & Liver & $3(60)$ \\
\hline & Kidney & $3(60)$ \\
\hline & Lung & $1(20)$ \\
\hline \multirow[t]{4}{*}{ Glycopeptides } & Liver & $34(73.91)$ \\
\hline & Kidney & $34(73.91)$ \\
\hline & Lung & $12(26.09)$ \\
\hline & Myocardium & $1(2.17)$ \\
\hline \multirow[t]{5}{*}{ Tetracycline } & Liver & $20(95.24)$ \\
\hline & Kidney & $14(66.67)$ \\
\hline & Lung & $9(42.86)$ \\
\hline & Myocardium & $4(19.05)$ \\
\hline & Endocrine & $4(19.05)$ \\
\hline \multirow[t]{4}{*}{ Lincosamide } & Liver & $3(100)$ \\
\hline & Kidney & $1(33.33)$ \\
\hline & Lung & $1(33.33)$ \\
\hline & Pancreatitis & $1(33.33)$ \\
\hline \multirow[t]{6}{*}{ Sulfonamide } & Liver & $17(73.91)$ \\
\hline & Kidney & $4(17.39)$ \\
\hline & Lung & $1(4.35)$ \\
\hline & Myocardium & $1(4.35)$ \\
\hline & Endocrine & $3(13.04)$ \\
\hline & Serositis & $1(4.35)$ \\
\hline \multirow[t]{3}{*}{ Nitrofurantoin } & Liver & $3(100)$ \\
\hline & Kidney & $3(100)$ \\
\hline & Lung & $3(100)$ \\
\hline \multirow[t]{2}{*}{ Linezolid } & Liver & $1(100)$ \\
\hline & Kidney & $1(100)$ \\
\hline \multirow[t]{2}{*}{ Daptomycin } & Liver & $1(100)$ \\
\hline & Kidney & $1(100)$ \\
\hline
\end{tabular}

Table 4 Comparison of patients' outcome between various antibiotic groups

\begin{tabular}{|c|c|c|}
\hline Antibiotic category & Outcome & $N(\%)$ \\
\hline \multirow[t]{3}{*}{ Penicillin } & Death & $1(4.55)^{*}$ \\
\hline & Complete resolution & $20(90.9)$ \\
\hline & Partial resolution & $1(4.55)$ \\
\hline \multirow[t]{2}{*}{ Cephalosporin } & Complete resolution & $9(90)$ \\
\hline & Partial resolution & $1(10)$ \\
\hline Carbapenem & Complete resolution & $3(100)$ \\
\hline Aminoglycoside & Complete resolution & $2(100)$ \\
\hline \multirow[t]{3}{*}{ Antituberculosis } & Death & $7(6.54)^{* *}$ \\
\hline & Complete resolution & 99 (92.52) \\
\hline & Partial resolution & $1(0.94)$ \\
\hline Macrolide & Complete resolution & $2(100)$ \\
\hline Fluoroquinolone & Complete resolution & $5(100)$ \\
\hline \multirow[t]{3}{*}{ Glycopeptide } & Death & $2(4.35)$ \\
\hline & Complete resolution & $43(93.48)$ \\
\hline & Partial resolution & $1(2.17)^{* * *}$ \\
\hline \multirow[t]{3}{*}{ Tetracycline } & Death & $4(19.05)$ \\
\hline & Complete resolution & $16(76.19)$ \\
\hline & Partial resolution & $1(4.76)^{* * *}$ \\
\hline \multirow[t]{2}{*}{ Lincosamide } & Death & $1(33.33)$ \\
\hline & Complete resolution & $2(66.67)$ \\
\hline \multirow[t]{3}{*}{ Sulfonamide } & Death & $1(4.35)$ \\
\hline & Complete resolution & $21(91.3)$ \\
\hline & Partial resolution & $1(4.35)^{* * * *}$ \\
\hline Nitrofurantoin & Complete resolution & $3(100)$ \\
\hline Linezolid & Complete resolution & $1(100)$ \\
\hline Daptomycin & Partial resolution & $1(100)^{* * * *}$ \\
\hline
\end{tabular}

*Underlying pneumonia may be the reason of death

**Two deaths out of five were strongly related to DRESS

*** She received liver transplant

****Disrupted LFT

The same reaction was reported after amoxicillin used in the patient with carbamazepine-induced DRESS, despite their chemical structure differences. The intradermal test to other beta-lactams was negative, defining a lack of cross-reactivity between amoxicillin and these drugs. Moreover, it should be noted that the second reaction usually is milder without organ involvement [32,33].

In summary, clinicians should be cautious when prescribing amoxicillin to a patient with a previous history of DRESS syndrome. Skin tests to beta-lactams should be done in such a patient to define whether the patient can tolerate these drugs [34]. The pathophysiology of the reaction remains uncertain and HHV-6 and HHV-7 or EBV reactivation has been proposed as a mediating factor. Amoxicillin itself or viral reactivation might affect, through an immune-mediated mechanism 
or a direct toxic effect, a response against the components of the cytochrome $\mathrm{P} 450$ enzymes, reducing their detoxifying capacity [4]. It is also noteworthy that rash following administration of amoxicillin in patients with infective mononucleosis is important differential diagnosis and should be elaborated further.

As a summary, penicillin-induced DRESS accounts for less than $10 \%$ of reported antibiotic-induced cases. Liver was the most involved organ (in more than $90 \%$ of cases). However, two cases of myocarditis caused by co-amoxiclav were reported. The outcome was favorable in reported cases and no death happened due to DRESS (one death occurred in a patient who experienced Pip/Taz-induced DRESS; however, it seems to be related to underlying pneumonia).

\section{Cephalosporins}

Just 10 cases of DRESS syndrome with cephalosporins are reported until now $(3.94 \%$ of all antibacterial antibioticreported DRESS cases) which most of them $(n=8)$ caused by third-generation cephalosporins. However, in a retrospective study from Korea in 2018, cephalosporins besides vancomycin and anti-TB medication are reported as the most common antimicrobial agents inducing DRESS [35]. Cefotaxime was known to cause the fewest adverse reactions among betalactam antibiotics [36]. However, some cases of DRESS are reported with this medication.

All patients managed with corticosteroid and antihistamines and just one case of cefuroxime-induced DRESS experienced hematuria for a long while after resolution of other symptoms. Moreover, like other beta-lactams, the liver and kidney were most reported organ involvements.

Fujiwaki et al. reported DRESS induced by cefotaxime and ampicillin. Fever occurred after 3 days but skin manifestation appears after 20 days [27]. There are some other case reports of cefotaxime-induced DRESS in adult and pediatric patients [37]. Aouam et al. reported a case of DRESS and also a case of DRESS-like syndrome (as no visceral involvement was found) [36].

Babu et al. reported the first case of cefpodoxime-induced DRESS syndrome, which the patient responded well to the steroid treatment [38].

The limited number of ceftriaxone-induced DRESS also is reported. In one case report, a 26-year-old patient who experienced DRESS with phenytoin reported sensitization to ceftriaxone after 2 months [33]. These kinds of reactions are reported in several cases with amoxicillin as mentioned above.

\section{Carbapenems}

Just three cases of carbapenem-induced DRESS are reported (1.18\% of all 254 reported cases). All three patients experienced liver involvement and all of them survived after corticosteroid therapy. The latency period was almost shortest for carbapenem-induced DRESS cases in comparison with other antibacterial agents (4 days).

Overall, it could be concluded that beta-lactam-induced DRESS is typically benign mostly involving the liver and could be completely reversed with corticosteroid therapy.

\section{Aminoglycosides}

There are just two cases of confirmed DRESS with aminoglycosides (AGs) to the best of our knowledge ( $0.79 \%$ of all 254 antibiotic-related DRESS cases). Passeron et al. reported DRESS induced by streptomycin when it was used as an antituberculosis agent beside isoniazid, rifampicin, and ethambutol. Fever, lymphadenopathy, and morbilliform rash, followed by exfoliative dermatitis with stomatitis, hypereosinophilia, atypical lymphocytes, and signs of hepatitis were the clinical manifestations. Streptomycin was the most probable causative agent, as the cutaneous rash and itching increment followed by fever and rise in hepatic enzymes noted promptly after its reintroduction [39].

It is noteworthy that despite AGs' bad reputation for nephrotoxicity, none of these two cases experienced kidney involvement. Both of them experienced hepatic involvement with completed resolution. The mean latency period also was longer than most of other antibiotic classes like betalactams.

\section{Antituberculosis}

As anti-TBs are well known for their hepatic and skin adverse effects independently, antituberculosis drug-associated DRESS has possibly been underdiagnosed and underreported for a few years [40]. However, actually, they compromised the largest part of antibacterial-reported DRESS cases, based on our searches. Out of total 254 cases summarized in this review, 107 cases were related to anti-TBs, which correspond to $42.13 \%$ of all cases. Rifampin (RIF) was the most reported offending agent among this category, followed by isoniazid (INH), ethambutol, and pyrazinamide, respectively [18, 40]. In a case series $(n=76)$, Allouchery et al. reported RIF ( $n=$ $60)$ and INH $(n=32)$ as the most common suspected drugs. However, excluding patients with a diagnosis other than tuberculosis who received RIF, INH was in the first place $(n=$ $32)$, followed by RIF $(n=30)$, then pyrazinamide $(n=25)$, and finally by ethambutol $(n=22)$. No dose-dependent pattern was found in this study. The mortality rate of DRESS was about $3 \%$, which is slightly higher than the previously reported rate $(1.7 \%)$. This may be due to delayed diagnosis since antituberculosis drugs are not the first to be suspected [40]. However, Jung et al. study reported a different frequency. They proposed ethambutol as the most common causative anti-TB (53.5\%), followed by RIF (26.7\%). The median 
latency of DRESS occurrence was 42 days. Moreover, there was a significant quantitative correlation between the RegiSCAR score and peak eosinophil count and a negative relationship between the RegiSCAR score and latency [41]. Based on this review, although the culprit medication for DRESS occurrence was not defined clearly in all collected case reports, considering reported data, rifampin followed by INH were most accused antituberculosis.

In another case series, 7 of the 11 studied patients were ethnically native South Americans, who are slow acetylator phenotypes for INH and a higher incidence of toxic hepatitis predominated. So, a genetic predisposition to DRESS syndrome may occur in this population [42].

As there is limited number of medication for the treatment of TB and they are used concomitantly in multi-drugs regimen, sometimes re-challenge is necessary to determine the exact culprit so treatment for TB can be continued. The drug re-challenging test is usually accepted as the gold standard for confirming the offending drug and minimizes unnecessary antituberculosis treatment discontinuation. In Palmero et al.'s study after drug discontinuation, they were reintroduced with a quarter of the initial dose and increased proportionally up to full dosage. The first medication was usually levofloxacin, followed by ethambutol. Only when these drugs were tolerated, reintroduction of INH and RIF were tried. It should be mentioned that a relapse of DRESS after the reintroduction of a culprit drug must be interpreted with caution [42]. Antituberculosis drugs could not be reintroduced until after the eosinophilia, rash, and toxic hepatitis had almost resolved. In comparison with the standard anti-TB regimen, the regimens after the resolution of DRESS syndrome comprised fewer drugs, with inferior antituberculosis activity [42].

Considering the differences in the chemical structure of antituberculosis medications, it is unlikely that there was cross-reactivity between them [40]. Lehloenya et al.'s study reported that the risk of cross-reactivity of isoniazid and ethionamide in DRESS syndrome is low [43].

Based on this review, the latency period is more than 1 month in average for anti-TB-induced DRESS and as these medications administered for several months in TB, the risk of DRESS occurrence is high. Moreover, various types of organ involvements other than liver and kidney are reported by these medication and mortality rate is almost higher in comparison with most of other antibiotic-induced DRESS (6.54\%).

\section{Macrolides}

Some reports of adults and pediatric patients with infectious mononucleosis or Epstein-Barr virus infection (IM; EBV) who developed generalized eruptions following treatment with azithromycin are available [44]. The incidence of skin rash is higher in the antibiotic-treated IM patients than those who do not take antibiotics and it is proposed that many of the previously noted cutaneous eruptions of IM were antibiotic eruptions in the setting of an altered immune state resulting from the EBV infection [45, 46]. Ampicillin was one of the first antibiotics which were connected to skin eruptions in IM. However, other antibiotics such as penicillin $\mathrm{G}$ or tetracycline also cause these reactions with much lower incidence. Later, other antibacterial drugs were also related to skin symptoms in IM, such as amoxicillin, talampicillin, or methicillin and few cases were reported about cephalexin, levofloxacin, erythromycin, and azithromycin [46]. The eruptions usually occur 210 days after starting the antibiotic treatment which is shorter than usual latency period for DRESS. Besides, no organ involvement occurs. This may result in a hypersensitivity reaction to an antigen, which in the case of antibiotics could manifest as a drug eruption [47]. Both the clinical and histological features confirm a delayed type hypersensitivity reaction [46].

Just two cases of probable DRESS with azithromycin are reported $(0.79 \%$ of 254 reviewed cases) and it seems that macrolides rarely are culprits for DRESS. Both reported cases occurred shortly after medication use (mean 5.5 days) and experienced kidney involvement but it resolved after corticosteroid therapy and supportive care.

\section{Fluoroquinolones}

Just 5 reports are available regarding DRESS induced by ciprofloxacin and levofloxacin (1.97\% of all 254 reviewed cases). The shorter latency period is a unique characteristic of (FQ) fluoroquinolone-induced DRESS syndrome. Alkhateeb et al. presented a case of ciprofloxacin-induced DRESS syndrome with a beginning of symptoms only 2 days after drug exposure [48]. It is interesting to note that the same finding is observed in idiosyncratic ciprofloxacin-induced liver injury [49]. However, based on this review, the mean latency period was $7.7 \mathrm{~d}$. Moreover, it seems that FQ-induced DRESS is mild and eventually is controlled a few days after drug discontinuation in many cases without any other intervention. However, the same outcome is reported in some other antibiotic groups like macrolides, aminoglycoside, carbapenems, and nitrofurantoin. Among visceral involvement, liver injury meaningfully less commonly occurred by FQs. Just 3 patients $(60 \%)$ experienced liver involvement, which occurred in more than $70 \%$ for DRESS induced by the other antibiotic groups except macrolides. It should also be mentioned that three patients experienced kidney involvement and one patient lung injury. The highest liver involvement frequency is reported by clindamycin and nitrofurantoin (three out 3 cases); however, considering the number of reported DRESS cases, it could be concluded that tetracyclines induced lots of liver injury and other organ involvements and had the highest mortality rate $(19.05 \%)$. 


\section{Glycopeptides}

Vancomycin may cause different adverse reactions including the "red man syndrome," erythema multiforme, vasculitis, allergic exanthema, anaphylaxis, agranulocytosis, thrombocytopenia, linear IgA bullous disease, and Stevens-Johnson syndrome/toxic epidermal necrolysis and also DRESS. Out of total 254 cases summarized in this review, 46 cases were related to vancomycin which corresponds to $18.11 \%$ of all cases. Most of the reported glycopeptide-induced DRESS belonged to vancomycin.

Cacoub et al.'s literature review found $2 \%$ of reported DRESS cases occurred with vancomycin [2]. It was first described in single case reports in 2005 and 2006, and subsequent case reports characterized the diagnosis and its association with HHV-6 reactivation. Moreover, the patient with the highest HHV-6 titers had a prolonged and severe clinical course [16]. Besides, Konvinse et al. proposed that HLA$A * 32: 01$ is severely associated with vancomycin-induced DRESS in a population of predominantly European ancestry [50].

DRESS syndrome happened within 2-5 weeks after starting vancomycin treatment [17]. In this review, we found a mean time of 21.23 days, which is shorter than anti-TBs and sulfonamides but much longer than beta-lactam latency time.

The age of patients who experienced DRESS with vancomycin is mentioned to be higher than other culprit drugs [35]. Risk factors for vancomycin-induced DRESS are prolonged therapy with vancomycin ( $>7$ days) and age $>40$ years [51].

In comparison with other antibacterial groups, vancomycin DRESS seems to have more renal involvement and is reported in about $75 \%$ of cases [52]. This is near to the percentage we found in this review (73.91\%). Vancomycin typically attributed to acute interstitial nephritis (AIN), and less usually has been associated with acute tubular necrosis (ATN) during DRESS. One case of vancomycin-induced ATN as a complication of DRESS is reported by Kim et al. [53]. Vancomycin trough levels $>15 \mathrm{mg} / \mathrm{L}$ are an independent predictor of nephrotoxicity, but any relationship with DRESS has not been examined [54]. Based on our review, just in 3 cases out of 13 patients who trough level of vancomycin was reported for them, the level was higher than recommended range $(23.08 \%)$. So, it seems that they may not be related. Pulmonary involvement was reported in 5\% of vancomycininduced DRESS [55]. Based on our data, kidney and liver involvements had the same prevalence $(73.91 \%)$, followed by lung damage $(26.09 \%)$ which is much higher than abovementioned prevalence. Kidney injury is a little bit more common with vancomycin which may be somewhat related to its nephrotoxic nature. However, contrary to this hypothesis, the nephrotoxic antibiotics, aminoglycosides, did not cause renal involvement as a complication of DRESS.
DRESS may be followed by antibody deficiency and autoimmune phenomena with other medications. For example, Wendland et al. reported that in a patient who experienced DRESS induced with vancomycin and daptomycin, agranulocytosis occurred with ceftobiprole, a fifth-generation cephalosporin [56].

Withdrawal of vancomycin and the use of systemic corticosteroids improved both cutaneous and systemic appearances of DRESS syndrome in most cases [16, 17]. Just two deaths related to DRESS are reported by glycopeptides (4.35\%), both of them caused by vancomycin.

It is important to note that the clinical presentation of DRESS may mimic ongoing or worsening sepsis, and consideration of alternative diagnoses such as DRESS beside sepsis is vital for optimal outcomes [16].

It should be considered that vancomycin used in bone cement does not have a significant role in the development of HSS/DRESS syndrome [57].

Teicoplanin, another glycopeptide antibiotic, also caused DRESS syndrome in limited number of patients. The onset of teicoplanin-induced DRESS ranges from 3 to 28 days. Reported cases have good outcomes, with all patients surviving after the instant withdrawal of the teicoplanin and supportive symptom treatment [58]. We found 7 cases with average latency period of 11.71 days and all of patients survived. Allergic cross-reactivity between vancomycin and teicoplanin has been reported infrequently [59]. Thus, hypersensitivity to vancomycin is not a contraindication to the use of teicoplanin if it was necessary [19]. However, Miyazu et al. described a case of DRESS with rash, interstitial pneumonitis, and eosinophilia caused by cross-reactivity between vancomycin and the following teicoplanin administration [59]. So, it is better to be cautious.

\section{Tetracyclines}

There were 21 cases of tetracycline-induced DRESS (8.27\% of antibiotic-induced DRESS cases) which most of them are related to minocycline, with long latency period in most of the cases (mean latency period of 28.48 days). Despite general safety records, doxycycline has been reported to have caused side effects, such as pseudotumor cerebri, AGEP, DRESS, and also Stevens-Johnson syndrome [60]. Just two cases of doxycycline-induced DRESS are reported to the best of our knowledge.

Minocycline-induced DRESS is related to various organ involvements including the liver, kidney, myocardium, lung, and endocrine system. Two concerning minocyclineassociated adverse reactions are autoimmunity and DRESS [61]. Although it has anti-inflammatory characteristics, the drug has been linked to many autoimmune disorders, including drug-induced lupus erythematosus, serum sickness-like reactions, vasculitis, and autoimmune hepatitis [62]. 
Minocycline-induced DRESS occurs generally in patients with Fitzpatrick skin phototypes V and VI. Patients with these phototypes had significant plasma and skin levels of minocycline even as long as several months after discontinuation of minocycline therapy. Melanin-minocycline complex formation may be the cause of this reaction in these patients [63]. Lung involvement seems to be more common in minocycline-induced DRESS [64]. We also found pulmonary involvement in about half of patients with tetracyclineinduced DRESS (42.86\%). However, the recent systematic review on pulmonary manifestations of DRESS syndrome has not found this association. They mentioned that lungs are less frequently involved in DRESS syndrome, but it may be related to a more severe clinical course and higher mortality [10]. Based on our review also, one-third of patients with lung involvement died (3/9).

In Brown et al.'s study, the patient experienced type 1 diabetes mellitus, Graves' disease, and positive antinuclear and anti-Smith antibodies during several months after minocycline exposure, suggesting a long-term immune system changes following DRESS rather than a short-term acute effect of minocycline [62]. It is believed that $\mathrm{T}$ regulatory ( $\mathrm{T}$ reg) cells play an important role and significantly increased during the acute stage of DRESS. Consequently, it increased immune suppression and at least in part have contributed to the autoimmunity. The combination of nonfunctional T-reg cells and viral reactivation can synergistically promote autoimmunity in an organ-specific or systemic manner. Moreover, some studies have linked DQA $1 * 0303$, DQB $1 * 0401$, and HLAB62 with fulminant T1DM after DRESS. Inherent immunomodulatory effect of minocycline is also important [65].

Hypersensitivity myocarditis, also known acute eosinophilic myocarditis (giant cell myocarditis [GCM]), is a rare potentially fatal manifestation of minocycline-induced DRESS reaction, and seven cases are reported until now. These specific organ failures lead to high mortality rate in comparison with other antibiotics induced DRESS (20\%).

Finally, it should be noted that there is a possibility of tetracycline cross-reactivity with DRESS, and any tetracycline including tigecycline should be avoided in patients with a history of tetracycline-associated DRESS [7].

\section{Lincosamide}

There is three reports of clindamycin induced DRESS out of all 254 reported cases $(1.18 \%)$. Tian et al. reported clindamycin induced DRESS without organ involvement which was successfully treated by oral prednisolone [66].

In a clindamycin induced DRESS case reported by Nakamura et al., there was no evidence of HHV-6, EBV, and CMV reactivation, but there is a probability that HHV-7 reactivation may contribute to the development of the reaction. As this patient had hypogammaglobulinemia, IVIG in addition to intravenous corticosteroid was prescribed. They expected that IVIG compensates for the decreased immunoglobulin concentration and besides the therapeutic effect of IVIG may be partially due to the presence of anti-viral $\operatorname{IgG}$ in it [67].

However, Quidley et al. represented a much more severe clindamycin induced DRESS syndrome that finally resulted in death. She developed an early rash and presented with concomitant renal and hepatic involvement. Her condition rapidly deteriorated despite the fast discontinuation of the medication and even IVIG administration. Hepatic involvement is proposed a predictor of poor prognosis in this patient [68]. However, the two other cases also experienced liver involvement but survived. Multi-organ failure including liver, kidney, pancreas and lung may cause death in this patient.

\section{Sulfonamides}

Sulfonamide antibiotics, particularly cotrimoxazole, are extensively associated with DRESS. Out of total 254 cases summarized in this review, 23 cases were related to sulfonamides, which correspond to $9.06 \%$ of all cases. However, the nonantibiotic sulfonamides like furosemide have not frequently been reported to cause DRESS syndrome. Different metabolic pathways of several sulfa-containing compounds which lead to dissimilar reactive metabolites with specific immunogenic reactivity could be a possible reason for abovementioned finding [69].

The liver was the main involved internal organ; however, a DRESS with multi-organ involvement was reported by dapsone. It is also noteworthy that in about half of the cases a viral reactivation was also present.

Gastrointestinal and hypersensitivity reactions are the main adverse reaction of trimethoprim/sulfamethoxazole (TMP/ SMX) and Stevens-Johnson syndrome, interstitial nephritis, toxic epidermal necrolysis, DRESS, agranulocytosis, and aplastic anemia are the most severe ones [70]. SMX is perhaps the responsible drug as it is a member of the sulfa groups of drugs, which can cause DRESS in association with HHV-6 [71]. N-acetyl-SMX, a SMX metabolite, is part of a potential route that makes immune cells more susceptible to react to certain drugs, resulting in the development of DRESS [70].

As mentioned above, TMP/SMX-induced fulminant hepatitis is a component of DRESS syndrome, occurring as soon as 1 day, or up to 6 weeks after first exposure and it managed usually successfully with corticosteroid and antihistamine use [72]. However, based on our review, the shortest latency period for TMP/SMX was 7 days.

Rueda-Valencia et al. reported a 4-year-old case with sickle cell anemia that experienced DRESS induced by TMP/SMX. The hypertransfusion treatment received by the patient might act as a predisposing factor [73]. 
Dapsone (4, 4'-diamino-diphenyl sulfone) is generally used in the treatment of inflammatory disease and infections such as Pneumocystis jiroveci pneumonia in patients with HIV infection, neutrophilic dermatoses, dermatitis herpetiformis, leprosy, and autoimmune bullous disease [74]. Dapsoneinduced DRESS rate is $0.2-0.5 \%$ and it has the longest latency period among antibiotics that induced DRESS (mean time 131 days based on available cases). The fever is almost reported in all patients who experienced DRESS induced by dapsone. Hepatitis, lymphadenopathy, and atypical lymphocytosis were also common [35]. In nonleprosy patients, the HLAB*13:01 allele was severely associated with dapsoneinduced DRESS [74]. This allele is mostly absent in Europeans and Africans, but it has an allele frequency of 1$12 \%$ in Indians, $2-4 \%$ in Southeast Asians, $1.5 \%$ in Japanese, and a markedly high prevalence of up to $28 \%$ in Australian Aborigines, Taiwanese, and Papuans [75].

It also should be mentioned that in one case of dapsoneinduced DRESS, it causes thyroiditis or myocarditis which are not common with most of the other antimicrobial agents [76].

Yusef reported a case of DRESS syndrome in a patient with toxoplasmosis infection, appearing during 8 weeks beginning of sulfadiazine [77].

It seems that no cross-reactivity occurred between different sulfonamides regarding DRESS syndrome [78].

\section{Other antibiotics}

Linezolid generally is well tolerated, except its thrombocytopenia and gastrointestinal side effects. A case of linezolid-induced DRESS happened after 7 days of use. The relatively short latency period in this report could be explained by earlier exposure to a single dose of linezolid on day 5 of hospitalization [79].

Three cases of nitrofurantoin induced DRESS are reported with liver, kidney, and lung involvements (1.18\% out of 254 reported antibiotic-induced DRESS cases). These reactions occurred shortly after nitrofurantoin use and completely resolved by routine measures. One report of daptomycin-induced DRESS is also available which occurred just 2 days after its administration with kidney and liver involvement. The patients' LFT did not completely resolve in follow-up period [80].

There are also many other cases of antimicrobial antibiotic induced DRESS, which are not mentioned in this review directly, but all of them are summerized in a table, presented as a supplementary file [81, 82-170].

\section{Limitations}

As we just included the English manuscripts, from limited electronic databases, a number of eligible studies may be missed out resulting in a selection bias. Moreover, as in some articles, the RegiSCAR score was not mentioned, and for the confirmation of the diagnosis, we decided to score the cases by ourselves. So, it is possible that in 15 omitted studies based on the criteria, some necessary information for the RegiSCAR score calculation were not mentioned in the article, and maybe they were definite or probable cases. Moreover, the RegiSCAR of reported cases are checked just by first author which was better to be done by two separate authors to minimize the selection bias.

\section{Conclusion}

In this review, 254 cases of antimicrobial antibiotic-induced DRESS with definite or probable diagnosis based on RegiSCAR criteria are collected. Most cases are related to anti-TBs, glycopeptides, and sulfonamides, respectively. The mean latency period was 29.26 days (range 2-300 days). The longest latency period was related to sulfonamides and antiTBs. Eosinophilia was the most reported hematologic involvement which occurred in about $93.7 \%$ of patients. Liver injury is the most defined type of organ damage (194 cases). Renal involvement was in the next place, which usually mild and recovered after medication discontinuation without permanent sequelae. The death occurred in 16 patients which most of them experienced hepatitis and/or pneumonitis. The highest mortality rate belonged to tetracyclines and anti-TB antibiotics. The reactivation of various viruses especially HHV-6 is reported in 33 cases. It is necessary to perform thorough epidemiological, genetic, and immunological studies, also systematic case review and causality assessment, as well as well-designed clinical trials for improving management of antibiotic-induced DRESS.

Acknowledgments This study is part of a research thesis for a Pharm.D. degree at Mashhad University of Medical Sciences.

Authors' contributions Shiva Sharifzadeh: Searched \& wrote the paper. Amir Hooshang Mohammadpour: Edited the manuscript. Ashraf Tavanaee: Edited the manuscript. Sepideh Elyasi: defined the manuscript's subject and searched \& edited the manuscript.

Funding The authors received financial support from Mashhad University of Medical Sciences, Mashhad, Iran.

\section{Compliance with ethical standards}

Conflict of interest The authors declare that they have no conflict of interest.

\section{References}

1. Fahim S, Jain V, Victor G, Pierscianowski T (2006) Piperacillintazobactam-induced drug hypersensitivity syndrome. Cutis 77 : 353-357

2. Cacoub P, Musette P, Descamps V, Meyer O, Speirs C, Finzi L et al (2011) The DRESS syndrome: a literature review. Am J Med 124(7):588-597 
3. Cabanas R, Calderon O, Ramirez E, Fiandor A, Prior N, Caballero $T$ et al (2014) Piperacillin-induced DRESS: distinguishing features observed in a clinical and allergy study of 8 patients. $\mathrm{J}$ Investig Allergol Clin Immunol 24(6):425-430

4. Girelli F, Bernardi S, Gardelli L, Bassi B, Parente G, Dubini A et al (2013) A new case of DRESS syndrome induced by sulfasalazine and triggered by amoxicillin. Case Rep Rheumatol 2013:409152

5. Sharpe A, Mourad BM, Hardwick J, Reilly T, Dweck E, Bondarsky E (2019) Oxacillin-induced drug reaction with eosinophilia and systemic symptoms (DRESS). Am J Case Rep 20: 345-348

6. Artuković M, Kuštelega J, Lugović-Mihić L (2010) DRESS syndrome with mild manifestations as a diagnostic and therapeutic problem: case report. Acta Clin Croatica 49(4):479-484

7. Robles DT, Leonard JL, Compton N, Waghmare A, McDonough KA, George E et al (2008) Severe drug hypersensitivity reaction in a young woman treated with doxycycline. Dermatology 217(1): $23-26$

8. Hagihara M, Yamagishi Y, Hirai J, Koizumi Y, Kato H, Hamada $Y$ et al (2015) Drug-induced hypersensitivity syndrome by liposomal amphotericin-B: a case report. BMC Res Notes 8:510

9. Descamps V, Valance A, Edlinger C, Fillet AM, Grossin M, Lebrun-Vignes B et al (2001) Association of human herpesvirus 6 infection with drug reaction with eosinophilia and systemic symptoms. Arch Dermatol 137(3):301-304

10. Taweesedt PT, Nordstrom CW, Stoeckel J, Dumic I (2019) Pulmonary manifestations of drug reaction with eosinophilia and systemic symptoms (DRESS) syndrome: a systematic review. Biomed Res Int 5:1-10

11. Díaz-Mancebo R, Costero-Fernandez O, Vega-Cabrera C, OleaTejero T, Yebenes L, Picazo ML et al (2012) Dress syndrome and acute tubulointerstitial nephritis after treatment with vancomycin and beta-lactams. Case report and literature review. Nefrología (English Edition) 32(5):685-687

12. Kardaun SH, Sekula P, Valeyrie-Allanore L, Liss Y, Chu CY, Creamer D et al (2013) Drug reaction with eosinophilia and systemic symptoms (DRESS): an original multisystem adverse drug reaction. Results from the prospective RegiSCAR study. Br J Dermatol 169(5):1071-1080

13. Littlehales E, Murray O, Dunsmuir R (2018) Vancomycininduced DRESS syndrome: an important concern in orthopedic surgery. Case Rep Orthop 2018:1439073

14. Shiohara T, Iijima M, Ikezawa Z, Hashimoto K et al (2007) The diagnosis of a DRESS syndrome has been sufficiently established on the basis of typical clinical features and viral reactivations. Br J Dermatol 156(5):1083-1084

15. Jurado-Palomo J, Cabañas R, Prior N, Bobolea ID, FiandorRomán AM, López-Serrano MC et al (2010) Use of the lymphocyte transformation test in the diagnosis of DRESS syndrome induced by ceftriaxone and piperacillin-tazobactam: two case reports. J Investig Allergol Clin Immunol 20(5):433

16. Blumenthal KG, Patil SU, Long AA (2012) The importance of vancomycin in drug rash with eosinophilia and systemic symptoms (DRESS) syndrome. Allergy Asthma Proc 33(2):165-171

17. Vauthey L, Uckay I, Abrassart S, Bernard L, Assal M, Ferry T et al (2008) Vancomycin-induced DRESS syndrome in a female patient. Pharmacology 82(2):138-141

18. Lee JY, Seol YJ, Shin DW, Kim DY, Chun HW, Kim BY et al (2015) A case of the drug reaction with eosinophilia and systemic symptom (DRESS) following isoniazid treatment. Tuberc Respir Dis (Seoul) 78(1):27-30

19. Boet S, Noblet C, Haas-Hubscher C, Picard D, Musette P, Dureuil B (2009) Severe vancomycin-induced drug rash with eosinophilia and systemic symptoms syndrome imitating septic shock. EJA 26(9):791-793
20. Wolfson AR, Zhou L, Li Y, Phadke NA, Chow OA, Blumenthal KG (2019) Drug Reaction with eosinophilia and systemic symptoms (dress) syndrome identified in the electronic health record. Allergy Module. J Allergy Clin Immunol Pract 7(2):633-640

21. Peyriere H, Dereure O, Breton H, Demoly P, Cociglio M, Blayac JP et al (2006) Variability in the clinical pattern of cutaneous sideeffects of drugs with systemic symptoms: does a DRESS syndrome really exist? Br J Dermatol 155(2):422-428

22. Eshki M, Allanore L, Musette P, Milpied B, Grange A, Guillaume $\mathrm{J}-\mathrm{C}$ et al (2009) Twelve-year analysis of severe cases of drug reaction with eosinophilia and systemic symptoms: a cause of unpredictable multiorgan failure. Arch Dermatol 145(1):67-72

23. Trubiano JA, Aung AK, Mary N, Fehily S, Graudins L, Cleland H et al (2016) A comparative analysis between antibiotic- and nonantibiotic-associated delayed cutaneous adverse drug reactions. J Allergy Clin Immunol Pract 4(6):1187-1193

24. van Kester MS, Langeveld TJC, Bouwsma H, van Rees JB, Holman ER, Teng YKO (2018) A breathtaking DRESS due to amoxicillin-clavulanate presenting as polymorphic eruption of the pregnancy. J Eur Acad Dermatol Venereol 32(12):e436-e437

25. Whitaker P, Rahnama-Moghadam S, Alomari AK, Haggstrom AN (2011) Mass spectrometric characterization of circulating and functional antigens derived from piperacillin in patients with cystic fibrosis. J Immunol 187(1):200-211

26. Shiohara T, Takahashi R, Kano Y (2007) Drug-induced hypersensitivity syndrome and viral reactivation, in Pichler, W.J. (Bern) (Ed.) Drug hypersensitivity (pp. 251-266). Basel: Karger Publishers.

27. Fujiwaki T, Yoshikawa T, Urashima R, Ishioka C (2008) Drug rash with eosinophilia and systemic symptoms induced by cefotaxime and ampicillin. Pediatr Int 50(3):406-408

28. Lang M, Fish J, Covelli C, Schreiber BE (2017) DRESS syndrome triple whammy: sulfasalazine, amoxicillin, and HHV-7. Br J Hosp Med 78(11):648-649

29. Sussman S, Devlin V, Dimitriades VR (2017) Dimitriades, A teenager with sulfasalazine-associated DRESS syndrome after the introduction of amoxicillin. Clin Pediatr 56(3):290-291

30. Mousa OY, Khalaf R, Shannon RL, Egwim CI, Zela SA, Ankoma-Sey V (2014) Chronic hepatitis C therapy in liver cirrhosis complicated by telaprevir-induced DRESS. Case Rep Med 2014:380424

31. Mardivirin L, Valeyrie-Allanore L, Branlant-Redon E, Beneton N, Jidar K, Barbaud A et al (2010) Amoxicillin-induced flare in patients with DRESS (drug reaction with eosinophilia and systemic symptoms): report of seven cases and demonstration of a direct effect of amoxicillin on Human Herpesvirus 6 replication in vitro. Eur J Dermatol 20(1):68-73

32. Aouam K, Fredj Nadia B, Amel C, Naceur B (2010) Amoxicillininduced hypersensitivity after DRESS to carbamazepine. World Allergy Organ J 3(7):220-222

33. Gaig P, Garcia-Ortega P, Baltasar M, Bartra J (2006) Drug neosensitization during anticonvulsant hypersensitivity syndrome. JIACI 16(5):321

34. Ben Fredj N, Aouam K, Chaabane A, Toumi A, Ben Rhomdhane F, Boughattas N (2010) Hypersensitivity to amoxicillin after drug rash with eosinophilia and systemic symptoms (DRESS) to carbamazepine and allopurinol: a possible co-sensitization. Br J Clin Pharmacol 70(2):273-276

35. Sim DW, Yu JE, Jeong J, Jung JW, KangHR KDY et al (2019) Variation of clinical manifestations according to culprit drugs in DRESS syndrome. Pharmacoepidemiol Drug Saf 28(6):840-848

36. Aouam K, Chaabane A, Toumi A, Ben Fredj N, Ben Romdhane F, Boughattas NA et al (2012) Drug rash with eosinophilia and systemic symptoms (DRESS) probably induced by cefotaxime: a report of two cases. Clin Med Res 10(1):32-35 
37. Kang H, Min TK, Yang HJ, Pyun BY (2016) Cefotaxime-induced drug rash with eosinophilia and systemic symptoms syndrome in a 7-year-old boy. Ann Allergy Asthma Immunol 117(2):202-204

38. Babu T, Panachiyil GM, Sebastian J, Shastry V (2019) Drug rash with eosinophilia and systemic symptoms (DRESS) syndrome probably related to cefpodoxime: a case report. J Pharm Pract: 897190019866094

39. Passeron T, Ndir MC, Aubron C, Hovette P (2004) Drug rash with eosinophilia and systemic symptoms (DRESS) due to streptomycin. Acta Dermato-Venereol Stockholm 84(1):92-92

40. Allouchery M, Logerot S, Cottin J, Pralong P, Villier C, Saïd BB (2018) Antituberculosis drug-associated DRESS: a case series. J Allergy Clin Immunol Pract 6(4):1373-1380

41. Jung HY, Park S, Shin B, Lee JH, Lee SJ, Lee MK (2019) Prevalence and clinical features of drug reactions with eosinophilia and systemic symptoms syndrome caused by antituberculosis drugs: a retrospective cohort study. Allergy, Asthma Immunol Res 11(1):90-103

42. Palmero D, Castagnino J, Musella RM, Mosca C, Gonzalez MP, de Casado GC (2013) Difficult clinical management of antituberculosis DRESS syndrome. Int J Tuberc Lung Dis 17(1):7678

43. Lehloenya RJ, Muloiwa R, Dlamini S, Gantsho N, Todd G, Dheda $\mathrm{K}$ (2015) Lack of cross-toxicity between isoniazid and ethionamide in severe cutaneous adverse drug reactions: a series of 25 consecutive confirmed cases. J Antimicrob Chemother 70(9): 2648-2651

44. Bauer KA, Brimhall AK, Chang TT (2011) Drug reaction with eosinophilia and systemic symptoms (DRESS) associated with azithromycin in acute Epstein-Barr virus infection. Pediatr Dermatol 28(6):741-743

45. Schissel DJ, Singer D, David-Bajar K (2000) Azithromycin eruption in infectious mononucleosis: a proposed mechanism of interaction. CUTIS-NEW YORK 65(3):163-166

46. Ónodi-Nagy K, Bata-Csörgo Z, Varga E, Kemény L, Kinyó A (2015) Antibiotic induced cutaneous rash in infectious mononucleosis: overview of the literature. J Allergy Ther 6:222

47. Dakdouki GK, Obeid KH, Kanj SS (2002) Azithromycin-induced rash in infectious mononucleosis. Scand J Infect Dis 34(12):939941

48. Alkhateeb H, Said S, Cooper CJ, Gaur S, Porres-Aguilar M (2013) DRESS syndrome following ciprofloxacin exposure: an unusual association. Am J Case Rep 14:526-528

49. Radovanovic M, Dushenkovska T, Cvorovic I, Radovanovic N, Ramasamy V, Milosavljevic K et al (2018) Idiosyncratic druginduced liver injury due to ciprofloxacin: a report of two cases and review of the literature. Am J Case Rep 19:1152

50. Konvinse KC, Trubiano JA, Pavlos R, James I, Shaffer CM, Bejan CA et al (2019) HLA-A* 32: 01 is strongly associated with vancomycin-induced drug reaction with eosinophilia and systemic symptoms. J Allergy Clin Immunol 144(1):183-192

51. Korman TM, Turnidge JD, Grayson ML (1997) Risk factors for adverse cutaneous reactions associated with intravenous vancomycin. J Antimicrob Chemother 39:371-381

52. Madigan LM, Fox LP (2019) Vancomycin-associated drug-induced hypersensitivity syndrome. J Am Acad Dermatol 81(1): $123-128$

53. Kim KM, Sung K, Yang HK, Kim SH, Kim HY, Ban GH, Park SE et al (2016) Acute tubular necrosis as a part of vancomycin induced drug rash with eosinophilia and systemic symptoms syndrome with coincident postinfectious glomerulonephritis. Korean J Pediatr 59(3):145-148

54. Gangireddy M, Sarao MS, Shrimanker I, Nookala VK (2019) A fatal case of vancomycin associated drug reaction with eosinophilia and systemic symptoms syndrome in a septuagenarian. Cureus 11(6):e5015
55. Wilcox O, Hassanein M, Armstrong J, Kassis N (2017) Case report: atypical presentation of vancomycin induced DRESS syndrome: a case report and review of the literature. BMC Pulm Med 17(1):217

56. Wendland T, Daubner B, Pichler WJ (2011) Ceftobiprole associated agranulocytosis after drug rash with eosinophilia and systemic symptoms induced by vancomycin and rifampicin. $\mathrm{Br} \mathrm{J}$ Clin Pharmacol 71(2):297-300

57. Güner MD, Tuncbilek S, Akan B, Caliskan-Kartal A (2015) Two cases with HSS/DRESS syndrome developing after prosthetic joint surgery: does vancomycin-laden bone cement play a role in this syndrome? BMJ Case Rep 2015:bcr2014207028

58. Hsiao SH, Chen HH, Chou CH, Lin WL, Liu Yeh PY, Wu TJ (2010) Teicoplanin-induced hypersensitivity syndrome with a preceding vancomycin-induced neutropenia: a case report and literature review. J Clin Pharm Ther 35(6):729-732

59. Miyazu D, Kodama N, Yamashita D, Tanaka H, Inoue S, Imakyure $O$ et al (2016) DRESS syndrome caused by crossreactivity between vancomycin and subsequent teicoplanin administration: a case report. Am J Case Rep 17:625-631

60. Mailhol C, Tremeau-Martinage C, Paul C, Godel A, Lamant L, Giordano-Labadie F (2010) Severe drug hypersensitivity reaction (DRESS syndrome) to doxycycline. Ann Dermatol Venereol 137(1):40-43

61. Wu PA, Anadkat MJ (2014) Fever, eosinophilia, and death: a case of minocycline hypersensitivity. Cutis 93(2):107-110

62. Brown RJ, Rother KI, Artman H, Mercurio MG, Wang R, Looney $\mathrm{RJ}$ et al (2009) Minocycline-induced drug hypersensitivity syndrome followed by multiple autoimmune sequelae. Arch Dermatol 145(1):63-66

63. Schnetzke U, Bossert T, Scholl S, Freesmeyer M, Hochhaus A, La Rosée P (2011) Drug-induced lymphadenopathy with eosinophilia and renal failure mimicking lymphoma disease: dramatic onset of DRESS syndrome associated with antibiotic treatment. Ann Hematol 90(11):1353-1355

64. Kano Y, Shiohara T (2009) The variable clinical picture of druginduced hypersensitivity syndrome/drug rash with eosinophilia and systemic symptoms in relation to the eliciting drug. Immunol Allergy Clin N Am 29(3):481-501

65. Lan J, Lahoti A, Lew DB (2016) A severe case of minocyclineinduced DRESS resulting in liver transplantation and autoimmune sequelae. Ann Allergy Asthma Immunol 116(4):367-368

66. Tian D, Mohan RJ, Stallings G (2010) Drug rash with eosinophilia and systemic symptoms syndrome associated with clindamycin. Am J Med 123(11):e7-e8

67. Nakamura Y, Watamatsu K, Muto M (2013) Drug-induced hypersensitivity syndrome induced by clindamycin. Acta Derm Venereol 93(1):83-84

68. Miller Quidley A, Bookstaver PB, Gainey AB, Gainey MD (2012) Fatal clindamycin-induced drug rash with eosinophilia and systemic symptoms (DRESS) syndrome. Pharmacotherapy 32(12): e387-e392

69. James J, Sammour YM, Virata AR, Nordin TA, Dumic I (2018) Drug reaction with eosinophilia and systemic symptoms (DRESS) syndrome secondary to furosemide: case report and review of literature. Am J Case Rep 19:163-170

70. Antia C, Persad L, Alikhan A (2017) Trimethoprimsulfamethoxazole-induced drug eruption with eosinophilia and systemic symptoms (DRESS). J Drugs Dermatol 16(10):10431046

71. Morimoto T, Sato T, Matsuoka A, Sakamoto T, Ohta K, Ando T et al (2006) Trimethoprim-sulfamethoxazole-induced hypersensitivity syndrome associated with reactivation of human herpesvirus-6. Intern Med 45(2):101-105

72. Ng CT, Tan CK, Oh CC, Chang JP (2013) Successful extracorporeal liver dialysis for the treatment of trimethoprim- 
sulfamethoxazole-induced fulminant hepatic failure. Singap Med J 54(5):e113-e116

73. Rueda-Valencia Mde L, Infante $\mathrm{S}$, Campos M, Belendez C, Saavedra Lozano J (2016) Trimethoprim-sulfamethoxazoleinduced DRESS syndrome in a 4-year-old child. Ann Allergy Asthma Immunol 116(4):366-367

74. Tempark T, Satapornpong P, Rerknimitr P, Nakkam N, Saksit N, Wattanakrai P et al (2017) Dapsone-induced severe cutaneous adverse drug reactions are strongly linked with HLA-B*13: 01 allele in the Thai population. Pharmacogenet Genomics 27(12): 429-437

75. Cai F, Lucas M, Yun J (2018) Dapsone-induced drug reaction with eosinophilia and systemic symptoms associated with HLAB*13:01. Intern Med J 48(3):363-364

76. Teo RY, Tay YK, Tan CH, Ng V, Oh DC (2006) Presumed dapsone-induced drug hypersensitivity syndrome causing reversible hypersensitivity myocarditis and thyrotoxicosis. Ann Acad Med Singap 35(11):833-836

77. Yusuf I (2013) Folinic acid/prednisone/pyrimethamine/sulfadiazine. Reactions 1480:20-30

78. Monge-Ortega OP, Cabanas R, Fiandor A, Dominguez-Ortega J, Gonzalez-Munoz M, Quirce S et al (2018) Overlap between DRESS syndrome and exanthema induced by sulfadiazine in a patient treated with sulfamethoxazole: utility of the lymphocyte transformation test for identification of the culprit drug. J Investig Allergol Clin Immunol 28(2):132-134

79. Savard S, Desmeules S, Riopel J, Agharazii M (2009) Linezolidassociated acute interstitial nephritis and drug rash with eosinophilia and systemic symptoms (DRESS) syndrome. Am J Kidney Dis 54(6):e17-e20

80. Della-Torre E, Yacoub MR, Pignatti P, Della-Torre F, Sabbadini MG, Colombo G (2013) et al Optimal management of DRESS syndrome in course of infectious endocarditis. Ann Allergy Asthma Immunol 110(4):303-305

81. Suswardana, Hernanto M, Yudani BAD, Pudjiati SR, Indrastuti N (2007) DRESS syndrome from cefadroxil confirmed by a positive patch test. Allergy 62(10):1216-1217

82. Orbak Z, Sepetcigil O, Karakelleoğlu C, Gülses S (2010) Penicillin V-induced drug rash with eosinophilia and systemic symptoms. WIMJ 59(6):722-725

83. Kim TI, Jeong KH, Shin MK, Kim NI (2016) Piperacillin/ tazobactam-associated hypersensitivity syndrome with overlapping features of acute generalized exanthematous pustulosis and drug-related rash with eosinophilia and systemic symptoms syndrome. Ann Dermatol 28(1):98-101

84. Moriceau F, Prothet J, Blaise BJ, Ben Said B, Page M, Ber CE et al (2016) DRESS syndrome in the ICU: when a patient is treated with multiple drugs. Case Rep Critic Care 2016:4

85. da Silva NR, Aguiar R, Azurara L et al (2016) DRESS syndrome secondary to amoxicillin and clavulanic acid - a pediatric case report. BAOJ Pediatr 2:022

86. Droz N, Thiebaut M, Terrier B, Bérézné A, Sogni P, Beuvon F et al (2013) Severe cholestatic hepatitis revealing a DRESS syndrome. Rev Med Internet 34(10):645-648

87. Gauer R, Hu C, Beaman L (2017) Fever, rash, and leukopenia in a 32-year-old man. Dx? J Fam Pract 66(10):E7-e10

88. Paydas S, Balal M, Kocabas F, Ay N (2017) Acute renal failure secondary to drug-related crystalluria and/or drug reaction with eosinophilia and systemic symptom syndrome in a patient with metastatic lung cancer. Saudi J Kidney Dis Transplant 28(4):934

89. Wutte N, Palfner M, Auer H, Ruckenbauer G, Valentin T, Seeber $\mathrm{K}$ et al (2014) Toxocarosis and putative DRESS syndrome in an oncological patient: a case report. Wien Klin Wochenschr 126(1): $51-55$
90. Takemoto K, Makino T, Mizawa M, Kubo Y, Shimizu T (2019) Missense mutation $\mathrm{Y} 449 \mathrm{H}$ of the K10 gene in a patient with severe epidermolytic ichthyosis. Eur J Dermatol 29(2):227-228

91. Watts TJ, Li PH, Haque R (2018) DRESS Syndrome due to benzylpenicillin with cross-reactivity to amoxicillin. J Allergy Clin Immunol Pract 6(5):1766-1768

92. Rabenkogo A, Vigue MG, Jeziorski E (2015) DRESS syndrome. Arch Pediatr 22(1):57-62 reaction

93. Picard M, Fernandez MI, Des Roches A, Begin P, Paradis J, Paradis L et al (2013) Ceftazidime-induced drug with eosinophilia and systemic symptoms (DRESS) complicated by hemophagocytic lymphohistiocytosis. J Allergy Clin Immunol Pract 1(4):409-412

94. Akcam FZ, Aygun FO, Akkaya VB (2006) DRESS like severe drug rash with eosinophilia, atypic lymphocytosis, and fever secondary to ceftriaxone. J Inf Secur 53(2):e51-e53

95. Guleria VS, Dhillon M, Gill S, Naithani N (2014) Ceftriaxone induced drug rash with eosinophilia and systemic symptoms. J Res Pharm Pract 3(2):72-74

96. Silva-Feistner M, Ortiz E, Rojas-Lechuga MJ, Muñoz D (2017) Síndrome de sensibilidad a fármacos con eosinophilia y síntomas sistémicos en pediatría: Caso clínico. Rev Chil Pediatr 88(1):158 163

97. Yıldırım Y, Kara AV, Yılmaz Z, Yıldırım R, Y1lmaz S, Kadiroglu AK et al (2016) Cefuroxime axetil related DRESS (drug reaction with eosinophilia and systemic symptoms) Syndrome. Eur J Gen Med 13(2):161-164

98. Goto M, Shimizu F, Takeo N, Okamoto O, Katagiri K, Ikewaki J et al (2010) Drug-induced hypersensitivity syndrome due to carbapenem antibiotics. J Dermatol 37(4):374-377

99. Macias E (2013) Imipenem/ioversol. Reactions 1448:20

100. Prados-Castano M, Pinero-Saavedra M, Leguisamo-Milla S, Ortega-Camarero M, Vega-Rioja A (2015) DRESS syndrome induced by meropenem. Allergol Immunopathol (Madr) 43(2):233235

101. Bensaid B, Rozieres A, Nosbaum A, Nicolas JF, Berard F (2012) Amikacin-induced drug reaction with eosinophilia and systemic symptoms syndrome: delayed skin test and ELISPOT assay results allow the identification of the culprit drug. J Allergy Clin Immunol 130(6):1413-1414

102. Lee SW, Yoon NB, Park SM, Lee SM, Um SJ, Lee SK et al (2010) Antituberculosis drug-induced drug rash with eosinophilia and systemic symptoms syndrome confirmed by patch testing. JIACI 20(7):631

103. Kaswala DH (2013) Drug rash with eosinophilia and systemic symptoms syndrome due to anti-TB medication. J Family Med Prim Care 2(1):83-85

104. Wang L, Li LF (2017) Difficult clinical management of antituberculosis DRESS syndrome complicated by MRSA infection: a case report. Medicine (Baltimore) 96(11):e6346

105. Coster A, Aerts O, Herman A, Marot L, Horst N, Kenyon C et al (2019) Drug reaction with eosinophilia and systemic symptoms (DRESS) syndrome caused by first-line antituberculosis drugs: two case reports and a review of the literature. Contact Dermatitis 81(5):325-331

106. Czapka M, Shukla S, Slosar-Cheah M, (2017) Urine trouble: genitourinary tuberculosis and subsequent DRESS syndrome. Case Reports bcr2017220440

107. Patil V, Pattar R, Ichalkaranji R (2014) DRESS syndrome secondary to the pyrazinamide-a rare case report. Int J Biomed Adv Res 5(6):322-323

108. Kombila UD, Ka W, Mbaye FB, Diouf NF, Fall L, Ouedraogo P et al (2018) DRESS syndrome secondary to pyrazinamide: an uncommon complication of tuberculosis treatment. Rev Mal Respir 35(1):69-73 
109. Arruti N, Arruti N, Villarreal O, Bernedo N, Audicana MT, Velasco M, Uriel O, Martinez A, Bellón T (2016) Positive allergy study (intradermal, patch, and lymphocyte transformation tests) in a case of isoniazid-induced DRESS. JIACI 26(2):119

110. Zhang SN, He QX, Yang NB, Ni SL, Lu MQ (2015) Isoniazidinduced drug rash with eosinophilia and systemic symptoms (DRESS) syndrome presenting as acute eosinophilic myocarditis. Intern Med 54(10):1227-1230

111. Navickaite I, Drulyte K, Kasinskaite S, Bubliauskas A, Dovidaitiene D (2019) Drug reaction with eosinophilia and systemic symptoms syndrome: a case report and literature review. Int J Case Rep 3(1):1-6

112. Bartakke S, Shinde V, Shrividya S (2016) Anti-tuberculosis treatment-induced drug rash with eosinophilia and systemic symptoms syndrome. Med J Dr DY Patil Univ 9(2):271

113. Lee JH, Park HK, Heo J, Kim TO, Kim GH, Kang DH et al (2008) Drug rash with eosinophilia and systemic symptoms (DRESS) syndrome induced by celecoxib and anti-tuberculosis drugs. J Korean Med Sci 23(3):521-525

114. Kim H, Bang ES, Seung-Kwan L, Lee JM (2016) DRESS syndrome and acute generalized exanthematous pustulosis induced by antituberculosis medications and moxifloxacin: case report. Int J Clin Pharmacol Ther 54(10):808-815

115. Jridi S, Azzeddine R, Bourkadi JE (2017) Le DRESS syndrome secondaire aux antituberculeux: à propos d'un cas. Pan African Med J 27:37

116. Sriratanaviriyakul N, Nguyen LP, Henderson MC, Albertson TE (2014) Drug reaction with eosinophilia and systemic symptoms syndrome (DRESS) syndrome associated with azithromycin presenting like a septic shock: a case report. J Med Case Rep 8:332

117. Sahnoun R, El Aïdli S, Zaïem A, Lakhoua G, Kastalli S, Daghfous R (2015) DRESS syndrome à la ciprofloxacin. Nephrol Ther 11(2):111-113

118. Pannu AK, Adarsh M, Sharma N (2017) Not all febrile critical illness with a rash are infective: drug reaction may be a mimic. Indian J Crit Care Med 21(4):229

119. Matsumoto T, Horino T, Inotani S, Ichii O, Terada Y (2019) Drug reaction with eosinophilia and systemic symptoms/drug-induced hypersensitivity syndrome (DRESS/DIHS) caused by levofloxacin in a patient with systemic scleroderma, rheumatoid arthritis, and Sjogren syndrome. Contact Dermatitis 80(4):253254

120. Zuliani E, Zwahlen H, Gullet F, Marone C (2005) Vancomycininduced hypersensitivity reaction with acute renal failure: resolution following cyclosporine treatment. Clin Nephrol 64(2):155158

121. Yazganoğlu KD, Özkaya E, Ergin-Özcan P, Cakar N (2005) Vancomycin-induced drug hypersensitivity syndrome. J Eur Acad Dermatol Venereol 19(5):648-650

122. Bajaj P, Prematta MJ, Ghaffari G (2011) A sixty-five-year-old man with rash, fever, and generalized weakness. Allergy Asthma Proc 32(1):e1-e3

123. O'Meara P, Borici-Mazi R, Morton AR, Ellis AK (2011) DRESS with delayed onset acute interstitial nephritis and profound refractory eosinophilia secondary to Vancomycin. Allergy, Asthma Clin Immunol 7(1):16

124. Young S, Ojaimi S, Dunckley H, Douglas MW, Kok J, Fulcher DA et al (2014) Vancomycin-associated drug reaction with eosinophilia and systemic symptoms syndrome. Intern Med J 44(7): 694-696

125. Bacal A, Humphrey T, Yousuf T (2015) Vancomycin-induced drug rash with eosinophilia and systemic symptoms. J Med Cases 6(5):201-204

126. Pal A, Sen S, Biswas A, Naser SM, Tripathi SK (2015) A rare case of DRESS syndrome caused by vancomycin. J Acute Med 5(3): $74-76$
127. Webb PS, Al-Mohammad A (2016) Enigma: infection or allergy? Vancomycin-induced DRESS syndrome with dialysis-dependent renal failure and cardiac arrest. BMJ Case Rep. https://doi.org/10. 1136/bcr-2016-215911

128. Nguyen K, Ahmed MS (2018) Drug rash with eosinophilia and systemic symptoms syndrome presenting after the initiation of staphylococcus hominis infectious endocarditis treatment: a case report and updated review of management considerations. Cureus 10(12):e3679

129. Maldonado D, Lakhani J (2019) Vancomycin-induced DRESS syndrome treated with systemic steroids in a 16-year-old male. SAGE Open Med Case Rep 7:2050313X19841704

130. Roy S, Goswamy VP, Barssoum KN, Rai D (2019) Vancomycininduced drug reaction with eosinophilia and systemic symptoms (DRESS) Syndrome masquerading as elusive sepsis. Case Reports Immunol 2019:1625010

131. Harper KD, Incavo SJ (2019) Drug reaction with eosinophilia and systemic symptoms syndrome after total knee arthroplasty infection and placement of antibiotic spacer. Arthroplast Today 5(2): 148-151

132. Zafar S, Pal S, Kanaparthy N (2018) Vancomycin-induced DRESS syndrome Masquerading as red man syndrome. Ann Allergy Asthma Immunol 121(5):S67-S68

133. Ercan N, Yeşillik S, Demirel F, Tırık N, Kartal Ö (2019) Haplotype analysis in a 16-year-old boy with vancomycininduced DRESS syndrome. Pediatr Dermatol 36(6):992-994

134. Yuan K, Awan KS, Long J (2020) Vancomycin-induced drug rash with eosinophilia and systemic symptoms (DRESS). BMJ Case Rep 13(2)

135. Maxfield L, Schlick T, Macri A, Thatcher JV (2017) Ancomycinassociated drug reaction with eosinophilia and systemic symptoms (DRESS) syndrome: masquerading under the guise of sepsis. Case Reports, 2017. p. bcr-2017-221898

136. Hewitson LJ (2019) Vancomycin induced DRESS syndrome (drug reaction with eosinophilia and systemic symptoms) in a patient with tricuspid endocarditis. BMJ Case Reports CP 12(9): e229590

137. Chamorro-Pareja N, Patel A, Youngberg G, Gonzalez-Estrada A (2018) Case of drug reaction with eosinophilia and systemic symptoms secondary to vancomycin. Case Reports, p. bcr-2018227378

138. Adike A, Boppana V, Lam-Himlin D, Stanton M, Nelson S, Ruff KC (2017) A mysterious DRESS case: autoimmune enteropathy associated with DRESS syndrome. Case Rep Gastrointest Med 2017:7861857

139. Mattoussi N, Ben AM, Essadam LG, Fitouri RZ, Ben SB (2017) Drug reaction With Eosinophilia and Systemic Symptoms (DRESS) Syndrome in children: a case report. JIACI 27(2):144 146

140. Song SM, Cho MS, Oh SH, Kim KM, Park YS, Kim DY et al (2013) Liver transplantation in a child with acute liver failure resulting from drug rash with eosinophilia and systemic symptoms syndrome. Korean J Pediatr 56(5):224

141. Ree N, Bloomberg GR, Dehner LP, Heidingsfelder JA, White AJ et al (2012) Vancomycin-induced DRESS with evidence of T-cell activation in a 22-month-old patient. Ann Allergy Asthma Immunol 109(4):280-281

142. Sousa JM, Nascimento H, Belfort RJ (2016) DRESS syndrome in ophthalmic patients. Arq Bras Oftalmol 79(3):192-194

143. Castellazzi ML, Esposito S, Claut LE, Daccò V, Colombo C (2018) Drug reaction with eosinophilia and systemic symptoms (DRESS) syndrome in two young children: the importance of an early diagnosis. Ital J Pediatr 44(1):93

144. Perrett C, McBride S (2004) Teicoplanin induced drug hypersensitivity syndrome. BMJ 328(7451):1292 
145. Ebrahimpour S, Mohammadi M, Gholami K (2017) Drug reaction with eosinophilia and systemic symptoms (DRESS) with teicoplanin: a case report. Drug Saf Case Rep 4(1):1

146. Ben Romdhane H, Chadli Z, Ben NF, Chaabane A, Boughattas NA, Aouam K et al (2018) Teicoplanin-induced DRESS syndrome: The importance of skin tests. Med Mal Infect 48(4):291293

147. Kwon HS, Chang YS, Jeong YY, Lee SM, Song WJ, Kim HB et al (2006) A case of hypersensitivity syndrome to both vancomycin and teicoplanin. J Korean Med Sci 21(6):1108-1110

148. Tamagawa-Mineoka R, Katoh N, Nara T, Nishimura Y, Yamamoto S (2007) DRESS syndrome caused by teicoplanin and vancomycin, associated with reactivation of human herpesvirus-6. Int J Dermatol 46(6):654-655

149. Favrolt N, Bonniaud P, Collet E, Fayard M, Rabec C, Camus C et al (2007) Severe drug rash with eosinophilia and systemic symptoms after treatment with minocycline. Rev Mal Respir 24(7):892-895

150. Maubec E, Wolkenstein P, Loriot MA, Wechsler J, Mulot C, Beaune P et al (2008) Minocycline-induced DRESS: evidence for accumulation of the culprit drug. Dermatology 216(3):200204

151. Shaughnessy KK, Bouchard SM, Mohr MR, Herre JM, Salkey KS (2010) Minocycline-induced drug reaction with eosinophilia and systemic symptoms (DRESS) syndrome with persistent myocarditis. J Am Acad Dermatol 62(2):315-318

152. Kanno K, Sakai H, Yamada Y, Iizuka H (2014) Drug-induced hypersensitivity syndrome due to minocycline complicated by severe myocarditis. J Dermatol 41(2):160-162

153. Becker BA, Caruthers CN, Jureidini S, Garrett JS (2015) Noninvasive management of myocarditis despite a negative gadolinium-enhanced cardiac mri in a 15 -year-old boy with minocycline triggered dress syndrome. J Allergy Clin Immunol 135(2):AB123

154. Crowell CS, Melin-Aldana H, Tan TQ (2008) Fever, rash, and hepatic dysfunction in a 3-year-old child: a case report. Clin Pediatr 47(5):517-520

155. Paitorn L (2016) Co-trimoxazole-induced DRESS syndrome: a case report. J Med Assoc Thail 99:S227-S230

156. Miyashita K, Shobatake C, Miyagawa F, Kobayashi N, Onmori R, Yonekawa $\mathrm{S}$ et al (2016) Involvement of human herpesvirus 6 infection in renal dysfunction associated with DIHS/DRESS. Acta Derm Venereol 96(1):114-115

157. Hagiya H, Iwamuro M, Tanaka T, Hasegawa K, Hanayama Y, Kimura $\mathrm{M}$ et al (2016) Reactivation of human herpes virus-6 in the renal tissue of a patient with drug-induced hypersensitivity syndrome/drug rash with eosinophilia and systemic symptoms (DIHS/DRESS). Intern Med 55(13):1769-1774
158. Kuschel SL, Reedy MS (2018) Cyclosporine treatment of drug reaction with eosinophilia and systemic symptoms (DRESS) syndrome: a case report and brief review of the literature 41-43

159. Holbrook MB, Glick J (2019) Drug reaction with eosinophilia and systemic symptoms (DRESS syndrome). J Emerg Med 56(5): 562-563

160. Maarouf M, Wickenheiser M, Krase JM, Wolter S, Shi VY (2018) Trimethoprim-sulfamethoxazole-induced drug reaction with eosinophilia and systemic symptoms in a child with congenital renal disease. Pediatr Dermatol 35(6):e391-e392

161. Garnier A, Kwon T, Peuchmaur M, Mourier O, Baudouin V, Deschênes $\mathrm{G}$ et al (2008) Acute renal failure in a 3-year-old child as part of the drug reaction with eosinophilia and systemic symptoms (DRESS) syndrome following hepatitis A. Pediatr Nephrol 23(4):667-669

162. Han XD, Koh MJ, Wong SMY (2019) Drug reaction with eosinophilia and systemic symptoms in a cohort of Asian children. Pediatr Dermatol 36(3):324-329

163. Yusuf IH, Sahare P, Hildebrand GD (2013) DRESS syndrome in a child treated for toxoplasma retinochoroiditis. J AAPOS 17(5): 521-523

164. Rim MY, Hong J, Yo I, Park H, Chung DH, Ahn JY et al (2012) Cervical lymphadenopathy mimicking angioimmunoblastic T-cell lymphoma after dapsone-induced hypersensitivity syndrome. Korean J Pathol 46(6):606-610

165. Avancini J, Maragno L, Santi CG, Criado PR (2015) Drug reaction with eosinophilia and systemic symptoms/drug-induced hypersensitivity syndrome: clinical features of 27 patients. Clin Exp Dermatol 40(8):851-859

166. Velema MS, Voerman HJ (2009) DRESS syndrome caused by nitrofurantoin. Neth J Med 67(4):147-149

167. Leão RN, Barreto P, Leão RR, Ribeiro JV (2013) Nitrofurantoin: cause of DRESS syndrome. BMJ Case Rep 2013:bcr2013008991

168. Singh J et al (2016) Drug reaction with eosinophilia and systemic symptoms syndrome associated with Nitrofurantoin. J Res Pharm Pract 5(1):70

169. Ramírez A, Abril JC, Cano J (2015) DRESS syndrome due to antibiotic therapy of osteoarticular infections in children: two case reports. Revista Española de Cirugía Ortopédica y Traumatología (English Edition) 59(5):360-364

170. Karakayalı B, Yazar AS, Çakir D, Cetemen A, Kariminikoo M, Deliloglu B et al (2017) Drug reaction with eosinophilia and systemic symptoms (DRESS) syndrome associated with cefotaxime and clindamycin use in a 6-year-old boy: a case report. Pan Afr Med J 28:218

Publisher's note Springer Nature remains neutral with regard to jurisdictional claims in published maps and institutional affiliations. 